\title{
MODIFIKASI BUCKET ELEVATOR 536 PADA PT X
}

\author{
Candra Damis Widiawaty ${ }^{1}$, Averoes Syahputra Agil, Bayu Chandra Hangesthi \\ Prodi Teknik Mesin, Jurusan Mesin, Politeknik Negeri Jakarta \\ Jalan Prof. Dr. G. A. Siwabessy, Kampus UI, Depok 16425 \\ e-mail:1'candamis@gmail.com
}

\begin{abstract}
In the production process at $P T X$, such as casting process, required raw material in the form of casting sand. The sand transport process is done by a machine called a Bucket Elevator. The current condition of Bucket Elevator at Plant 2 PT X had some problems on its design due to the initial modification process to the machine that were deliberately done in order to ease the process of troubleshooting and repair on the machine to adjust the height of the drum shaft supported by the bearing, however, the modification causes a sand leak that impacted the lifetime of the bearing. The damage that occurs to the bearing of the Bucket Elevator can slow the production process at PT X down, which lasts between 120 hours to 134 hours per week. Therefore, it is necessary to modify the design of the Bucket Elevator machine in order to stop the sand leakage and be able to work optimally. The design modifications made, are changes to the shaft height adjusting mechanism of the Bucket Elevator 536 drum machine by providing a lock to minimize the leakage of sand that occurs and replace the bearing type to the type that is equipped with a seal to prevent the entry of sand into the bearings. The result of this modification can extend the lifetime bearing, thereby reducing production costs due to bearing replacement, and easing the troubleshooting and repairing process of the engine to adjust the height of the drum shaft supported by the bearings.
\end{abstract}

Key words : Bucket Elevator, Bearing, Modified

\begin{abstract}
ABSTRAK
Proses produksi pada PT X, seperti proses casting, diperlukan bahan baku berupa pasir casting. Proses pengangkutan pasir tersebut dilakukan oleh mesin Bucket Elevator. Kondisi mesin Bucket Elevator pada area Plant 2 PT. $X$ saat ini, memiliki beberapa masalah desain akibat proses modifikasi awal mesin yang sengaja dirubah untuk mempermudah proses troubleshooting dan perbaikan mesin untuk mengatur ketinggian shaft drum yang ditopang oleh bearing, namun terjadi kebocoran pasir yang berdampak pada lifetime bearing. Kerusakan yang terjadi pada bearing mesin Bucket Elevator dapat menghambat proses produksi pada PT. $X$ yang berlangsung antara 120 dan 134 jam/minggu. Oleh karena hal tersebut, diperlukan modifikasi desain mesin Bucket Elevator agar tidak mengalami kebocoran dan mampu bekerja secara optimal. Modifikasi desain yang dilakukan adalah perubahan pada mekanisme pengaturan ketinggian shaft drum mesin Bucket Elevator 536 dengan memberikan pengunci untuk meminimalisir kebocoran pasir yang terjadi dan mengganti tipe bearing yang dilengkapi dengan seal untuk mencegah masuknya pasir yang bocor ke dalam bearing. Hasil modifikasi desain dapat memperpanjang lifetime bearing, sehingga mengurangi biaya produksi akibat penggantian bearing, dan memudahkan proses troubleshooting serta perbaikan mesin untuk mengatur ketinggian shaft drum yang ditopang oleh bearing.
\end{abstract}

Kata kunci : Bucket Elevator, Bearing, Modifikasi

\section{PENDAHULUAN}

PT X merupakan industri yang bergerak dalam bidang pengecoran dan permesinan yang menghasilkan produk berupa Komponen Otomotif Kendaraan Komersial dan Kendaraan Penumpang serta komponen aftermarket dan Non Otomotif yang terkait konsumen dengan menerapkan teknologi dan keterampilan yang dikembangkan di bidang otomotif dan juga pengecoran logam.

Dalam proses produksi pada PT X, seperti proses casting, diperlukan bahan baku berupa pasir casting. Proses pengangkutan pasir tersebut dilakukan oleh mesin Bucket Elevator. Kondisi saat ini mesin Bucket Elevator 
mengalami kebocoran, karena proses modifikasi mesin untuk memudahkan proses troubleshooting dan perbaikan mesin untuk mengatur ketinggian shaft drum yang ditopang oleh bearing, namun modifikasi tersebut menimbulkan permasalahan yaitu kebocoran pasir yang berdampak pada lifetime bearing. Umur bearing menjadi lebih cepat yaitu hanya 30 hari dikarenakan penggunaan tipe bearing yang kurang tepat untuk proses foundry dan masuknya pasir ke dalam bearing mengakibatkan friksi antara pasir dengan bearing. Mesin bucket elevator dapat dilihat pada Gambar 1.

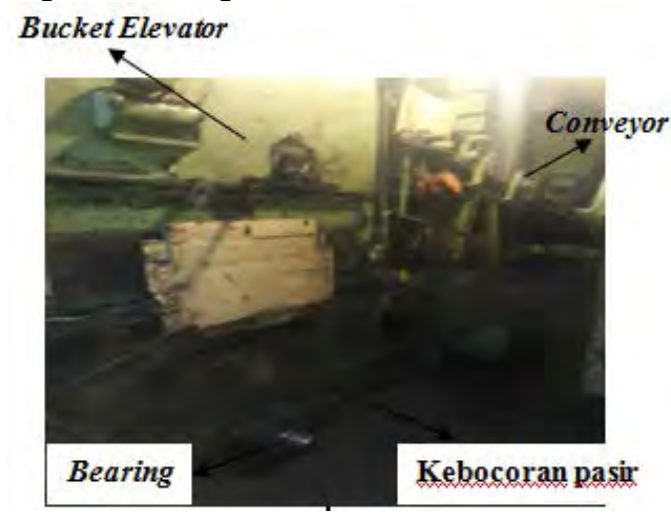

Gambar 1. Bucket elevator kondisi terpasang

Kerusakan yang terjadi pada bearing mesin Bucket Elevator dapat meghambat proses produksi pada plant 2 PT X yang berlangsung antara 120 dan $134 \mathrm{jam} / \mathrm{minggu}$. Oleh hal tersebut, mesin Bukcet Elevator harus mampu beroperasi semaksimal mungkin agar proses produksi dapat berjalan sesuai target.

\section{METODE PENELITIAN}

Langkah penyelesaian penelitian ini adalah :

- Persiapan dilakukan dengan pengumpulan data, survey dan studi literature

- Identifikasi konsumen dan penentuan spesifikasi dilakukan untuk mendapatkan beberapa aternatif desain yang sesuai dengan kebutuhan.

- Setelah mendapatkan beberapa alternatif desain, maka dilakukan pemilihan desain berdasarkan peringkat fungsi dan kelayakan untuk diproduksi.

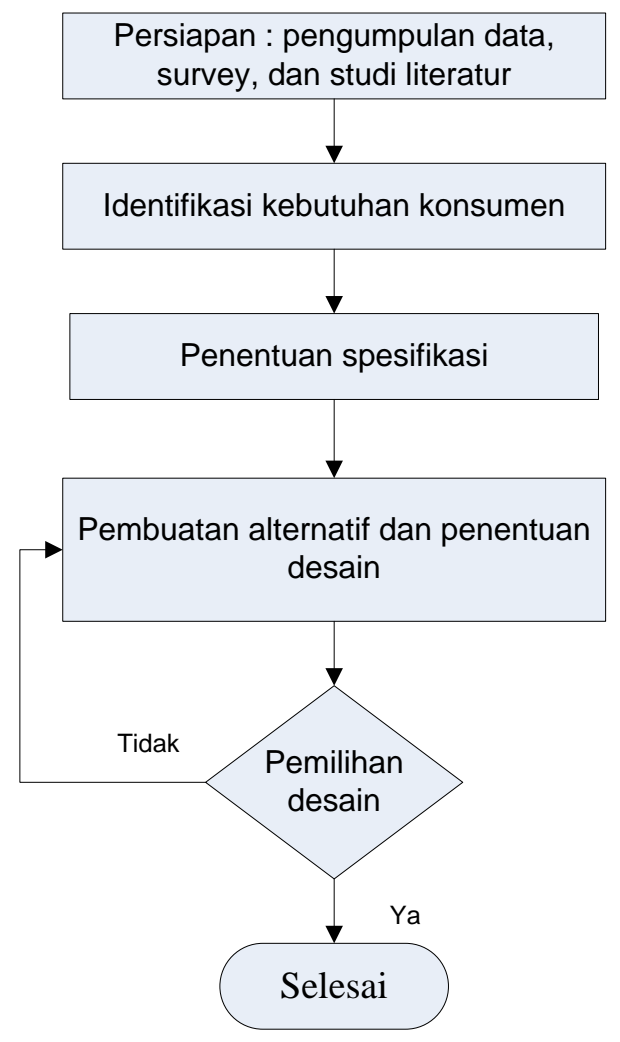

Gambar 2. Diagram alir penelitian

\section{HASIL dan PEMBAHASAN}

Hasil survei menunjukkan kebocoran akibat modifikasi sistem pemberat yang awalnya bertujuan untuk mempermudah trouble shooting, namun modifikasi tersebut menyebabkan celah pada penututup bearing, sehingga terjadi kebocoran mesin yang berdampak terhadap efisiensi kerja dan pergantian bearing setiap 30 hari. Hasil analisis kebutuhan konsumen ditunjukkan oleh Gambar 3.

Gambar 3 menunjukkan urutan modifikasi desain yang dibutuhkan oleh konsumen secara berturut-turut dari tertinggi hingga terendah umur bearing, perawatan mudah, keamanan operator, 
kesejajajaran poros, pencapaian produksi, dan biaya rendah. Berdasarkan hasil tersebut, maka dilakukan modifikasi pada mekanisme pengaturan ketinggian shaft drum dan modifikasi tipe bearing.

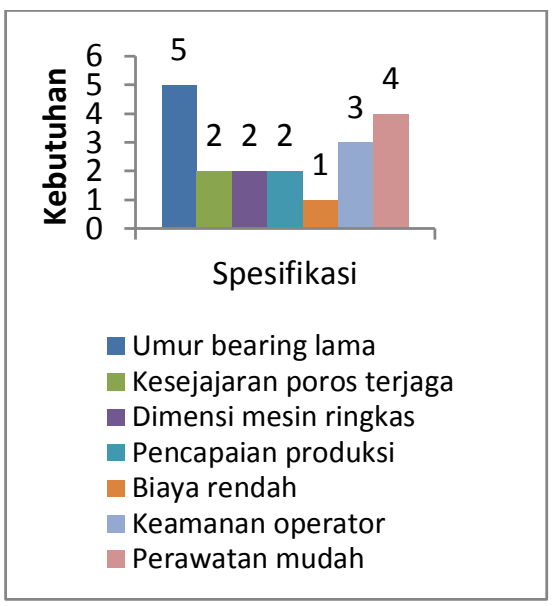

Gambar 3. Grafik kebutuhan konsumen

Beberapa alternatif desain yang dibuat sebagai berikut :
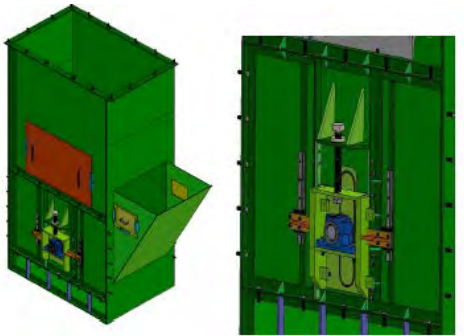

Gambar 4. Desain alternatif 1

Desain alternatif 1 menggunakan linier gage dan ulir trapesium pada bearing holder yang memberikan kepresisian yang tinggi dalam pengaturan ketinggian dan kesejajaran shaft drum, mekanisme ini menggunakan bearing tipe SE213 yang dilengkapi dengan seal pada bearing untuk mencegah masuknya pasir ke dalam bearing.
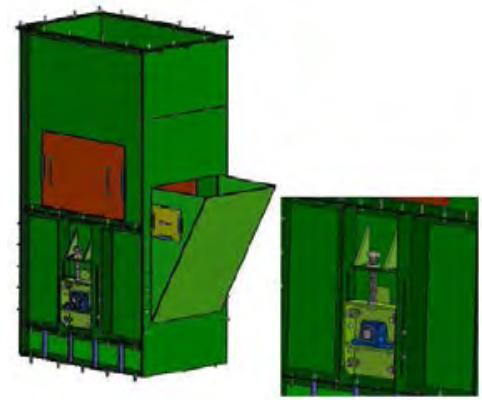

Gambar 5. Desain alternatif 2

Desain alternatif 2 menggunakan siku struktural pelat body bucket elevator yang dijadikan sebagai jalur jalannya bearing holder, pengaturan ketinggian dan penjagaan kesejajaran shaft drum dilakukan menggunakan ulir trapesium, mekanisme ini menggunakan bearing tipe SE213 yang dilengkapi dengan seal pada bearing untuk mencegah masuknya pasir kedalam bearing.
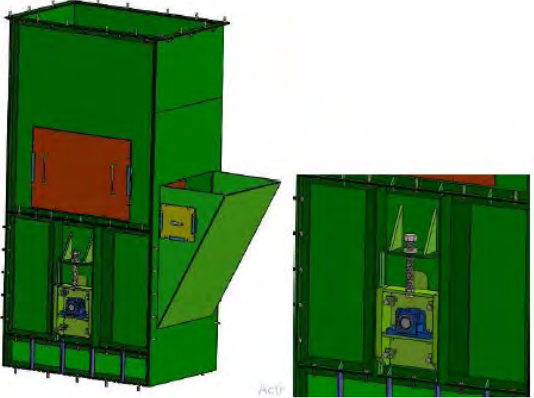

Gambar 6. Desain alternatif 3

Desain alternatif 3 hanya menggunakan ulir trapesium untuk pengaturan ketinggian shaft drum dan menggunakan jalur penuntun untuk jalan housing, kesejajaran shaft drum dijaga dengan pengaturan pada ulir trapesium, mekanisme ini menggunakan bearing tipe SE213 yang dilengkapi dengan seal pada bearing untuk mencegah masuknya pasir kedalam bearing. Baut pengunci dipasang pada bearing holder untuk menutup celah dan mencegah kebocoran pasir melalui celah antara bearing holder dan mesin bucket elevator. Alternatif ini menggunakan jalur yang terbuat dari baja S50C di dalam area bearing holder untuk jalur pengaturan ketinggian shaft drum.

Tabel 1. Perbandingan ketiga alternatif desain

\begin{tabular}{|c|c|c|c|c|c|}
\hline \multirow[t]{2}{*}{ No } & \multirow[t]{2}{*}{ Keterangan } & \multirow{2}{*}{$\begin{array}{l}\text { Desain } \\
\text { terpasang }\end{array}$} & \multicolumn{3}{|c|}{ Alternatif } \\
\hline & & & 1 & 2 & 3 \\
\hline 1 & $\begin{array}{l}\text { Tipe } \\
\text { bearing }\end{array}$ & UCP213 & \multicolumn{3}{|l|}{ SE213 } \\
\hline 2 & $\begin{array}{l}\text { Pengaturan } \\
\text { ketinggian } \\
\text { shaftdrum }\end{array}$ & Bandul & \multicolumn{3}{|c|}{ Ulir trapesium } \\
\hline 3 & $\begin{array}{l}\text { Penutup } \\
\text { kebocoran } \\
\text { pasir }\end{array}$ & Tidak ada & Seal & Pela & \\
\hline 4 & $\begin{array}{l}\text { Jalur } \\
\text { pengaturan }\end{array}$ & Tidak ada & $\begin{array}{l}\text { Linear } \\
\text { gage }\end{array}$ & Pela & $50 \mathrm{C}$ \\
\hline
\end{tabular}




\begin{tabular}{|l|l|l|l|l|l|}
\hline & $\begin{array}{l}\text { ketinggian } \\
\text { shaft drum }\end{array}$ & & & \multicolumn{2}{|l|}{} \\
\hline 5 & $\begin{array}{l}\text { Posisi jalur } \\
\text { pengaturan } \\
\text { ketinggian } \\
\text { shaft drum }\end{array}$ & Tidak ada & $\begin{array}{l}\text { Di luar } \\
\text { area } \\
\text { holder } \\
\text { bea } \\
\text { ring }\end{array}$ & $\begin{array}{l}\text { Pada } \\
\text { siku pe } \\
\text { nyangga } \\
\text { holder } \\
\text { bearing }\end{array}$ & $\begin{array}{l}\text { Di } \\
\text { dalam } \\
\text { area } \\
\text { holder } \\
\text { bearing }\end{array}$ \\
\hline
\end{tabular}

Tabel 2. Screening matriks modifikasi mesin bucket elevator 536

\begin{tabular}{|l|l|l|l|l|}
\hline No & Kriteria & $\mathbf{1}$ & $\mathbf{2}$ & $\mathbf{3}$ \\
\hline $\mathbf{1}$ & Umur bearing lama & & & 1 \\
\hline $\mathbf{2}$ & Kesejajaran poros terjaga & 1 & & \\
\hline $\mathbf{3}$ & dimensi mesin ringkas & 1 & 1 & 1 \\
\hline $\mathbf{4}$ & Pencapaian produksi & & & 1 \\
\hline $\mathbf{5}$ & Biaya rendah & & 1 & \\
\hline $\mathbf{6}$ & Keamanan operator & 1 & & \\
\hline $\mathbf{7}$ & Perawatan mudah & & 1 & 1 \\
\hline & Total & $\mathbf{3}$ & $\mathbf{3}$ & $\mathbf{4}$ \\
\hline
\end{tabular}

Berdasarkan Tabel 2, maka alternatif 3 yang dijadikan acuan modifikasi, langkah selanjutnya perhitungan mekanik sebagai berikut :

- Umur bearing

$$
\begin{aligned}
L & =\left(\frac{C}{W}\right)^{k} \times \frac{10^{6}}{60 n} \ldots \ldots \ldots \ldots(1) \ldots \ldots \\
L & =\left(\frac{44000}{4414}\right)^{3} \times \frac{10^{6}}{60 \times 398.08} \\
L & =41734 \mathrm{jam} \\
L & =1700 \text { hari }
\end{aligned}
$$

Keterangan :

$$
C=\text { Beban dinamis }(\mathrm{kN})
$$

$W=$ Berat total $(\mathrm{N})$

$n=$ putaran mesin (rpm)

$L=$ umur bearing (hari)

Dengan demikian alternatif desain memiliki umur bearing selama 1700 hari

- Menentukan diameter minimum baut

$$
\begin{aligned}
& d c=\sqrt{\frac{4 \times W_{\text {total }}}{\pi \times \sigma_{t} / S_{f} \times n_{\text {baut }}}} \ldots \\
& d c=\sqrt{\frac{4 \times 112984}{\pi \times 400 / 4 \times 2}} \\
& d c=26.8 \mathrm{~mm}
\end{aligned}
$$

$$
d c=28.7 \mathrm{~mm}=M 33
$$

Keterangan :

$d c=$ Diameter minimum $(\mathrm{mm})$

$P=$ Beban yang bekerja pada baut

$(\mathrm{N})$

$\sigma_{t}=$ Kekuatan tekan $(\mathrm{N})$

$S f=$ Faktor keamanan

$n_{\text {baut }}=$ jumlah baut (pcs)

- Jumlah Ulir dan Tinggi Ulir

$$
\begin{aligned}
& n_{\text {ulir }}=\frac{W}{\pi \times d_{c} \times t \times \tau_{s}} \ldots(3) \\
& n_{\text {ulir }}=\frac{56491.7}{\pi \times 28.7 \times 1.925 \times 180} \\
& \quad n_{\text {ulir }}=1.81 \\
& H=0.7 d \\
& H=0.7 \times 33 \\
& H=23.1 m m \\
& \text { Keterangan : } \\
& \tau_{s}=\text { kekuatan tarik }(\mathrm{N}) \\
& H=\text { tinggi ulir }(\mathrm{mm}) \\
& t=\text { pitch }
\end{aligned}
$$

- Ketebalan las

$$
\begin{aligned}
& s=\frac{F \times S_{f}}{2 \times \tau_{g} \times 1 \sin 45 \ldots \ldots \ldots(4)} \\
& s=\frac{2207.3 \times 4}{2 \times 0.45 \times 9.8 \times 2.104 \sin 45} \\
& s=1.36 \mathrm{~mm}
\end{aligned}
$$

Keterangan :

$$
\begin{aligned}
& s=\text { tebal pengelasan }(\mathrm{mm}) \\
& \mathrm{l}=\text { panjang pengelasan }(\mathrm{mm})
\end{aligned}
$$

\section{KESIMPULAN}

Hasil penelitian ini melakukan modifikasi perancangan bucket elevator seperti berikut : mengganti sistem pengaturan ketinggian shaft drum dengan ulir trapesium, memberikan seal untuk mencegah kebocoran ke poros, membuat jalur pengaturan ketinggian shaft drum dari material pelat baja S50C yang letaknya di dalam area holder bearing, dan mengubah tipe bearing menjadi SE213. 


\section{UCAPAN TERIMA KASIH}

Terima kasih atas fasilitas yang telah diberikan oleh PT Bakrie Autoparts, sehingga penelitian ini dapat selesai.

\section{DAFTAR PUSTAKA}

[1] Budianto, et al. 2014. Rancang bangun bucket elevator pengangkat gabah. Jurnal Teknik Pertanian Lampung, vol. 3, No. 1, pp. 17- 26.

[2] Hamsi, Alfian. , 2009, "Studi Variasi Sudut Kemiringan Bucket Elevator Pabrik Kelapa Sawit Kapasitas Pabrik 30 ton tbs/jam Hubungannya dengan Daya Motor, Kecepatan Bucket dan Kapasitas Bucket”, Jurnal Dinamis Vol. II, No. 4, pp. 53- 58.

[3] Irawan, Dani. 2017. Perancangan Prototype Bucket Elevator. Jurnal Ilmiah Multitek Indonesia, Vol. 11, No. 1, pp. 1- 11.

[4] Katalog “ASTM Steel”, 2018.

[5] Katalog “Tabel Produk SKF”, 2018.

[6] Khurmi, R.S., dan J.K. Gupta. 2005. A text book of Machine Design. New Delhi: Eurasia Publishing House (Pvt) Ltd.

[7] Spyvakovsky, A., dan V. Dyachkov. 1964. Conveyor and Related Equipment. Moscow: Peace Publishers.

[8] Sularso dan Kyokatsu Suga. 1997. Dasar Perencanaan dan Pemilihan Elemen Mesin. Jakarta: Pradnya Paramitha.

[9] Ulrich, Karl T., dan Steven D. Eppinger. Perancangan \& Pengembangan Produk. Jakarta: Salemba Teknika. 
Candra Damis W, Averoes Syahputra A dan Bayu Chandra H, Modifikasi Bucket Elevator... 